\title{
Transatlantica
}

Revue d'études américaines. American Studies Journal

\section{Richard Godbeer. Sexual Revolution in Early America, Baltimore (Md).}

The Johns Hopkins University Press, 2002, 430p.

\section{Éliane Elmaleh}

\section{OpenEdition}

Journals

Édition électronique

URL : http://journals.openedition.org/transatlantica/733

DOI : $10.4000 /$ transatlantica.733

ISSN : 1765-2766

Éditeur

AFEA

Référence électronique

Éliane Elmaleh, « Richard Godbeer. Sexual Revolution in Early America, Baltimore (Md). », Transatlantica [En ligne], 1 | 2003, mis en ligne le 05 avril 2006, consulté le 29 avril 2021. URL : http://

journals.openedition.org/transatlantica/733; DOI : https://doi.org/10.4000/transatlantica.733

Ce document a été généré automatiquement le 29 avril 2021.

\section{c) (i) $\Theta$}

Transatlantica - Revue d'études américaines est mis à disposition selon les termes de la licence Creative Commons Attribution - Pas d'Utilisation Commerciale - Pas de Modification 4.0 International. 


\title{
Richard Godbeer. Sexual Revolution in Early America, Baltimore (Md).
}

The Johns Hopkins University Press, 2002, 430p.

\author{
Éliane Elmaleh
}

1 Cet ouvrage, au titre provocateur, dévoile la complexité et la surprenante multiplicité des comportements sexuels dans l'Amérique coloniale. L'objectif principal de l'auteur est de révéler l'existence d'un clivage persistant entre théorie et pratique, entre l'affichage d'une Amérique puritaine dont les idéologies officielles et les normes morales ont été reconstruites au travers de décrets gouvernementaux, lois, décisions juridiques, sermons, traités théologiques ou encore littérature didactique, et une Amérique sexuellement subversive, celle sur laquelle Godbeer a choisi de se pencher en analysant par exemple les témoignages scandalisés des pasteurs et hommes d'église qui découvraient les pratiques sexuelles dans le Nouveau Monde. Godbeer met donc en avant une autre facette de l'Amérique coloniale, une Amérique où les relations sexuelles avant ou hors mariage n'étaient pas scandaleuses mais au contraire courantes, et qui contredit fortement l'image stéréotypée de l'abstinence puritaine véhiculée par l'imaginaire national. Correspondances privées, journaux intimes (tenus par une élite d'hommes blancs lettrés), rapports d'affaires juridiques à caractère sexuel, journaux et magazines populaires - qui en exposant les scandales et crimes sexuels ont pu donner la parole à des points de vue alternatifs et divulguer des informations sur des comportements interdits - sont ainsi passés en revue pour redéfinir la "culture sexuelle " de l'époque. Godbeer est un historien qui a choisi de mener une étude des mœurs sexuelles sur le territoire des colonies Britanniques sur deux siècles, de la période coloniale aux premières décennies de la République. Cet ouvrage ne se veut pas une étude générale de la sexualité, c'est plutôt une sélection de cas qui permettent de mieux comprendre le rôle qu'elle a pu avoir, son impact et la place qu'elle a eu dans l'architecture morale et culturelle de la société, ainsi que la façon dont ont évolué les controverses durant une période où l'imposition d'un ordre moral paraissait d'autant plus urgent que l'environnement primitif dans lequel les colons se retrouvaient, semblait, pour les tenants d'un ordre moral, encourager les tendances barbares et avilissantes, pouvant mener à une dégénération culturelle symbolisée par la présence 
des Indiens, et par la suite des Africains qui menaçaient de contaminer les colons et compromettre leur civilisation. L'auteur montre bien que la sexualité etait perçue comme le symbole des multiples dangers auxquels étaient exposés les colons durant une période marquée par l'incertitude politique, économique et culturelle, et la raison pour laquelle elle devint la cible principale de ceux qui pensaient que le péché et le chaos menaçaient les colonies.

INDEX

Thèmes : Recensions

AUTEUR

ÉLIANE ELMALEH

Université du Maine, Le Mans 